\title{
Anti-aanvalsbehandelingen bij kinderen: nieuw en hip, ook nuttig?
}

Het is beter om het over anti-aanvalsmedicatie te hebben dan over anti-epileptica, omdat de medicijnen die epileptische aanvallen bestrijden de onderliggende aandoening niet genezen. Nieuwe behandelingen zijn vaak populair, maar niet alles wat door een registratieonderzoek komt, verdient ook een plaats in de behandeling. In deze bijdrage worden drie nieuwe anti-aanvalsbehandelingen besproken en hun plaats in de behandelalgoritmes.

\section{Behandeling van focale aanvallen}

Focale aanvallen bij kinderen worden behandeld met eerste keus medicijnen als lamotrigine, levetiracetam, carbamazepine (CBZ) en anderen. Na twee middelen lang genoeg en voldoende gedoseerd te hebben toegepast, wordt zo nodig de optie epilepsiechirurgie bezien. Het komt vaak voor dat we bij kinderen starten met CBZ. Maar op den duur kan dit osteoporose geven met een verhoogde kans op botbreuken (Suljic et al., 20I8). Lacosamide (LCM) is net als CBZ een natriumkanaalblokker. In een gerandomiseerde, dubbelblinde, non-inferiority trial toonden Baulac et al. (2017) aan dat met LCM een even hoog percentage volwassenen met een nieuw gediagnostiseerde epilepsie aanvalsvrij raakt als met CBZ. Onlangs toonden Farkas et al. (2019) in een gerandomiseerde, placebo-gecontroleerde add-on trial bij kinderen met refractaire focale aanvallen de meerwaarde in aanvalsreductie aan van LCM boven placebo. Vergeleken met placebo gaf LCM vaker sufheid en duizeligheid. Doordat LCM geen inductie of remming geeft van cytochroom P45o enzymen, veroorzaakt LCM geen osteoporose. LCM, lamotrigine, levetiracetam of oxcarbazepine hebben daarom de voorkeur bij het behandelen van een kind met focale aanvallen.

\section{Behandeling van juveniele myoclonus epilepsie} Valproïnezuur, topiramaat en perampanel (PMP) worden bij voorkeur niet ingezet bij jonge vrouwen met juveniele myoclonus epilepsie (JME) omdat deze middelen met een zwangerschap een verhoogd risico geven op aangeboren afwijkingen. Voor valproïnezuur en topiramaat is dat risico bij mensen aangetoond, voor PMP is dat voor mensen nog niet bekend, maar er is indicatie van teratogeniteit bij rattenonderzoek (Serafini et al., 2019). Hierdoor is het aantal behandelmogelijkheden bij jonge vrouwen met JME beperkt en lukt het vaak niet om met name gegeneraliseerde tonisch-clonische aanvallen onder controle te krijgen.

Brodie (20r6) adviseert om bij vrouwen met JME eerst een poging te doen met levetiracetam en dan met lamotrigine. Mocht levetiracetam niet worden verdragen, dan heeft het op basis van de retrospectieve cohortstudie van Strzelczyk et al. (2018) zin om off label een poging te doen met brivaracetam. Als er nog steeds sprake is van geregeld tonisch-clonische aanvallen zonder uitlokkend moment (zoals slaapgebrek of het vergeten van medicatie), dan zijn modified Atkins dieet, acetazolamide, nervus vagus stimulatie, valproïnezuur, topiramaat en PMP de volgende behandelopties. Mocht voor PMP worden gekozen, dan is de vraag of effectiviteit en veiligheid voldoende zijn onderzocht bij adolescenten met JME. In de registratietrial had PMP, vergeleken met placebo, effect op tonisch-clonische aanvallen maar niet op myoclonieën en absences (French et al., 2015). Op basis van een retrospectief dossieronderzoek is echter onlangs aangetoond (Villanueva et al., 2015) dat PMP dit effect wel heeft. Het ging om adolescenten en volwassenen die onvoldoende baat hadden gevonden bij andere in aanmerking komende anti-epileptica. PMP werd toegevoegd. Na één jaar gebruikte $83 \%$ nog steeds PMP en was van de oorspronkelijke groep $59 \%$ aanvalsvrij voor tonisch-clonische aanvallen, myoclonieën en absences. Bijwerkingen bestonden uit slaperigheid, duizeligheid en bij 28\% prikkelbaarheid.

De conclusie is dat PMP bij jonge vrouwen met JME een optie kan zijn wanneer de behandelingen met minder kans op bijwerkingen zonder succes waren. Een bijwerking van PMP is prikkelbaarheid. Over PMP in de zwangerschap is onvoldoende bekend; een zwangerschap moet dus worden ontraden.

Cannabidiol bij Dravet- en Lennox-Gastautsyndroom Cannabis bevat tetrahydrocannabinol (THC) en cannabi- 
diol (CBD). THC is psychoactief. Cannabis met een hoog THC-gehalte en relatief laag CBD-gehalte lijkt de kans op een psychotische reactie te vergroten. CBD mist het psychoactieve effect van THC en heeft anti psychotische eigenschappen. Het effect van CBD bij epilepsie komt enerzijds tot stand door neuronale effecten: op ionkanalen, op neuronale receptoren en beïnvloeding van de reuptake in neuronen. Anderzijds worden de leverenzymen beïnvloed, waardoor het andere medicatie potentieert (met name clobazam).

De onderzoeken naar de effectiviteit en veiligheid van CBD bij kinderen met epilepsie zijn verricht met het uit Engeland afkomstige, onlangs op de Europese markt toegelaten CBD-GW ${ }^{\mathrm{I}}$.

Wereldwijd hebben 318 kinderen met Dravet-syndroom (DS) in de leeftijd van twee tot achttien jaar en 396 patiënten met Lennox Gastaut-syndroom (LGS) in de leeftijd van twee tot vijfenvijftig jaar deelgenomen aan placebogecontroleerde trials met CBD-GW waarin de behandeling veertien weken duurde. Er is een open label vervolg geweest van één jaar. De bevindingen van de trials waar SEIN Zwolle met 32 patiënten aan heeft deelgenomen, zijn door Devinsky en door Thiele et al. (2017-2019) gepubliceerd en zullen dit jaar worden gepresenteerd op de American Epilepsy Society Meeting. Bij SEIN Zwolle gebruiken op dit moment dertien kinderen, na deelname aan bovengenoemde trials en met toestemming van de Inspectie, CBD-GW.

De bijwerkingen van CBD-GW die in de trials het vaakst voorkwamen waren sufheid, verminderde eetlust, diarree en stijging van de transaminases. Die laatste bijwerking was de meest voorkomende reden om met CBD-GW te stoppen en kwam vooral voor bij patiënten die naast CBDGW op valproïnezuur stonden. Verlagen van de dosis van één van beide of beide medicijnen hief de transaminasestijging vaak op (Franco \& Perucca, 20I9).

CBD drijft N-desmethyl-clobazam op en andersom drijft clobazam (CLB) de CBD-spiegel op. De impact van de interactie tussen CBD en CLB is voor de DS-trials niet goed in te schatten omdat veel kinderen stiripentol gebruikten en CBD de stiripentol-plasma-spiegel met $55 \%$ verhoogt (Franco \& Perucca, 2019). Op basis van de gegevens van de LGS-trials is aannemelijk gemaakt dat het anti-aanvalseffect van CBD-GW onafhankelijk van de interactie met CLB tot stand komt: het percentage patiënten dat 50\% of meer aanvalsreductie bereikte bedroeg in de met CLB behandelde groep $46 \%$ bij gebruik van CBD en $19 \%$ bij ge- bruik van een placebo. Zonder CLB waren die percentages $33 \%$ en $8 \%$. Van de patiënten met het LGS die geen CLB gebruikten, had $67 \%$ het eerder wel gehad.

In de Verenigde Staten bepaalde de Food and Drug Administration dat CBD-GW zonder clobazam mag worden toegepast. De European Medicines Agency bepaalde echter dat CBD-GW bij patiënten met DS en LGS in combinatie met CLB moet worden toegepast.

Dit leidt tot de volgende aanbeveling: combineer bij kinderen met DS en LGS CBD-GW met CLB, indien het kind CLB verdraagt. Veel kinderen verdragen CLB niet en vertonen als bijwerking prikkelbaarheid en boze buien. Inmiddels is ook bij patiënten met tubereuze sclerose complex in een trial de meerwaarde ten opzichte van placebo aangetoond (report GW Pharmaceuticals 6-5-2019) en zijn in het Amerikaanse expanded access program vergelijkbare effecten en bijwerkingen gevonden bij kinderen met $\mathrm{CDKL}_{5}$, Aicardi syndroom, Dupi5q en Doose syndroom (Devinsky et al., 2018).

Het is nu afwachten of de producent CBD-GW gaat aanmelden bij het Zorginstituut Nederland, zodat aan de minister van VWS advies kan worden uitgebracht inzake toelating. Binnen afzienbare tijd is in de behandeling van kinderen met DS en LGS ook de toelating tot de Europese markt te verwachten van fenfluramine. Belangrijk is welke plaats de nieuwe geneesmiddelen gaan innemen in de bestaande behandelalgoritmen. Voor DS is die te vinden in Richt-lijnendatabase.nl, voor LGS in Cross et al. (20I7).

\section{Tot slot}

CBZ kan osteoporose geven. Overweeg daarom ook bij jongeren alternatieve medicatie, onder meer LCM. Overweeg bij jonge vrouwen met een JME en veel tonisch-clonische aanvallen een behandeling met PMP. CBD heeft in registratietrials zijn nut bewezen bij het Dravet- en Lennox Gastaut-syndroom en komt mogelijk ook in Nederland beschikbaar. Benut eerst de al beschikbare behandelopties.

\section{Referenties}

Brodie MJ (20I6) Modern management of juvenile myoclonic epilepsy. Expert Review of Neurotherapeutics 2016;16:681-688.

Cross JH, Auvin S, Falip M et al. (2017) Expert opinion on the management of Lennox-Gastaut syndrome: treatment algorithms and practical considerations. Front Neurol 2017;8:505.

${ }^{1}$ GW-pharmaceuticals heeft een nagenoeg THC-vrij CBD-product ontwikkeld (CBD-GW) dat onder de naam Epidyolex in de handel is gebracht (in de Verenigde Staten gespeld als Epidiolex). Er bestaan geen epilepsiestudies met CBD die geproduceerd wordt onder auspiciën van het ministerie van VWS. Hiervan is de THC- en CBD-samenstelling gegarandeerd. Van de elders verkrijgbare CBD is de samenstelling vaak niet bekend en deze kan wisselen. Het toenemend aantal meldingen van hallucinaties, onrust en paniek bij het Nationaal Vergiftigingen Informatie Centrum zijn waarschijnlijk toe te schrijven aan de THC in deze ongecontroleerde producten. 
Devinsky O, Verducci C, Thiele EA et al. (2018) Open-label use of highly purified CBD (Epidiolex®) in patients with $\mathrm{CDKL}_{5}$ deficiency disorder and Aicardi, Dupi5q, and Doose syndromes. Epilepsy \& Behavior 2018;86:131-137.

Farkas V, Steinborn B, Flamini JR et al. (20I9) Efficacy and tolerability of adjunctive lacosamide in pediatric patients with focal seizures. Neurology 2019;93:e1212-e1226.

Franco V, Perucca E (20I9) Pharmacological and therapeutic properties of cannabidiol for epilepsy. Drugs 2019;79:1435-1454.

French JA, Krauss GL, Wechsler RT et al. (2015) Perampanel for tonic-clonic seizures in idiopathic generalized epilepsy: A randomized trial. Neurology 2015;85:950-957. Multidisciplinaire richtlijn Dravetsyndroom Vereniging Klinische Genetica Nederland. www.Richtlijnendatabase. nl 2019.
Serafini A, Gerard E, Genton P et al. (20rg) Treatment of juvenile myoclonic epilepsy in patients of child-bearing potential. CNS Drugs 2019;33:195-208.

Strzelczyk A, Kay L, Bauer S et al. (2018) Use of brivaracetam in genetic generalized epilepsies and for acute, intravenous treatment of absence status epilepticus. Epilepsia 2018;59:1549-1556.

Suljic EM, Mehicevic A, Mahmutbegovic N (2018). Effect of long-term carbamazepine therapy on bone health. Med Arch 2018;72:262-266.

Villanueva V, Montoya J, Castillo A et al. (2018) Perampanel in routine clinical use in idiopathic generalized epilepsy: The I2 month GENERAL study. Epilepsia 2018;59:17401752.

Door: Eline van Hugte ${ }^{\mathrm{I}, 2,3}$ (elinevanhugte@radboudumc.nl), moleculaire neurofysiologie; Judith Verhoeven ${ }^{\mathrm{I}}$, kinderneurologie; Jurgen Schelhaas ${ }^{4}$, neurologie; Jason Keller², 3, moleculaire neurofysiologie; Elly Lewerissa ${ }^{2}$, 3, moleculaire neurofysiologie; Hans van Bokhoven 2, 3, moleculaire neurogenetica; Nael Nadif Kasri², 3, moleculaire neurofysiologie; Marian Majoie ${ }^{\mathrm{I}, 5}$, neurologie.

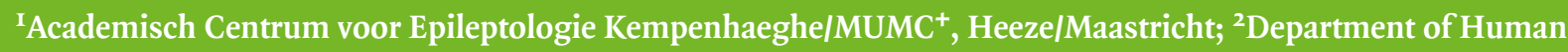
Genetics, Radboudumc, Nijmegen; ${ }^{3}$ Donders Institute for Brain, Cognition and Behaviour, Centre for Neuroscience, Radboud Universiteit Nijmegen; 4Stichting Epilepsie Instellingen Nederland (SEIN), Zwolle; 5 School of Mental Health and Neuroscience en School of Health Professions Education, Maastricht Universitair Medisch Centrum $\left(\mathrm{MUMC}^{+}\right)$

\section{De pluripotente stamceltech- niek: de mogelijkheid om patiënt-eigen neuronen te bestuderen in het lab}

In steeds meer onderzoeken naar neuronale ontwikkelingsstoornissen wordt gebruik gemaakt van humaan geïnduceerde pluripotente stamcellen. Deze techniek maakt het mogelijk om vanuit somatische cellen (zoals bloed- en huidcellen) stamcellen te verkrijgen die gedifferentieerd kunnen worden naar patiënt-eigen neuronale cellen. Naast het bestuderen van ziektemechanismes lenen deze neuronale cellen zich ook voor het testen van medicijnen op een patiëntspecifieke manier.

Wat is de toepasbaarheid van neuronen afkomstig uit humaan geïnduceerde pluripotente stamcellen (hIPSCs) voor onderzoek naar neuronale ontwikkelingsstoornissen, zoals epileptische encephalopathieën (EEE)? De EEE behoren tot een heterogene groep van moeilijk behandelbare epilepsieën die vaak voor het eerste levensjaar tot uiting komen. Er treden verschillende soorten aanvallen op, maar ook als er geen aanvallen zijn werken de hersenen niet goed, hetgeen een negatieve invloed heeft op de ontwikkeling van het kind. EEE kunnen ontstaan door verschillende oorzaken, maar worden symptomatisch gekenmerkt door een medicatieresistente epilepsie. Het voortbestaan van de epileptische activiteit draagt bij aan de cognitieve achteruitgang en gedragsstoornissen en 